\title{
Reconsidering the role of the digital in global production networks
}

\author{
CHRISTOPHER FOSTER ${ }^{*}$ AND MARK GRAHAM ${ }^{\dagger}$ \\ *(corresponding author), Information School, University of Sheffield, \\ Regent Court, 211 Portobello, Sheffield, S1 4DP \\ christopherfoster@sheffield.ac.uk \\ ${ }^{\dagger}$ Oxford Internet Institute, University of Oxford, \\ 1 St Giles, Oxford, OX1 3JS \\ mark.graham@oii.ox.ac.uk
}

\begin{abstract}
Global production networks (GPNs) have become a key framework in conceptualizing linkages, power and structure in globalized production. However, this framework has been less successful in integrating the influence of digital information and ICTs in production, and this problematic in a world where relationships and power are increasingly mediated by digital information flows and resources. We thus look to adapt the GPN framework to allow more substantive analysis of 'the digital'. Primarily, this is done through a theoretical analysis of the three core categories of the GPN framework-embeddedness, value and networks to highlight how these categories can better integrate a more dynamic and contested conceptualization of the digital. Illustrations from research on the digitalization of tea sector GPNs in East Africa highlight how these theoretical advances provide new insights on the digital and its expanding role in economic production.
\end{abstract}

Keywords GLOBAL PRODUCTION NETWORKS, INFORMATION AND COMMUNICATION TECHNOLOGY, INTERNET, NETWORK SOCIETY, SUB-SAHARAN AFRICA

Global production networks (GPNs) have become a key framework in conceptualizing linkages and crucially uneven power and structure in globalized production (Coe and Yeung 2015; Henderson et al. 2002). The GPN framework explores the economic relations of actors directly involved in economic production, as well as a wider gamut of networked relationships, institutions and policy that orientate the forms and practices of production.

This article originates from research exploring changing practices around digital information flows, digital data and information and communication technologies

This is an open access article under the terms of the Creative Commons Attribution License, which permits use, distribution and reproduction in any medium, provided the original work is properly cited.

Global Networks 17, 1 (2017) 68-88. ISSN 1470-2266. (C) 2016 The Author(s) 
(ICTs) in production - we will refer to this socio-technical bundle of activities as 'the digital' (as outlined in the next section). In previous research we explored the impacts that the digital might play in reconfiguring production, with a particular interest on lowincome producers in the Global South.

Initially, the GPN framework seemed an appropriate choice. It would allow us to conceptualize the broader relationships and power related to the producers we were examining, and it would form a basis for understanding how the digital might disrupt economic structures and relationships. Yet, in practice, in its current form, we found that the GPN framework provided only limited analytical value in our investigations.

As has been detailed elsewhere (Foster and Graham 2015b, 2015c; Waema and Katua 2014), our empirical research findings have suggested that the digital is an increasingly contested element of production. Active exclusionary practices have led to overt contestation around access to digital information flows, and services (for example where agri-business actors make it difficult for smallholder farmers to access information resources). Meanwhile, less visible affordances and functioning of ICTs and digital software subtly reinforce the disadvantages that small firms have (for example global tourism services where requirements for digitalization often exclude small firms). These findings, namely that the digital becomes a 'site' of contestation and uneven relations, were difficult to integrate into core usage of the GPN framework and thus, for all its explanatory potential, we found limited guidance on integrating the digital resources as an important role into GPN analysis.

In this article, we argue that the poor explanatory power of the GPN framework to understand the digital is more than an isolated issue for our specific research. We found limited conceptual literature on this topic and, while the literature often acknowledges that the digital plays an important role in tying together increasingly geographically dispersed production networks, it rarely explores the digital as anything more than an infrastructural component. There is a disparity between the relative absence of research and the fact that digital data flows and services are increasingly central to the efficient management and monitoring of global dispersed networks. Innovation and competitive advantage in production are increasingly associated with the rollout and integration of digital services, digital networks, and online applications (Malecki and Moriset 2007).

Therefore, it is important to analyse critically the role of the digital in shaping global production. In this article, we thus seek to understand better how to embed the digital within thinking about GPNs and pose the following research question: how can the GPN framework best capture the important roles that the digital plays in shaping GPNs?

The article is set out as follows: it first introduces the ways that the GPN literature has discussed ICTs and digital flows of information and defines the terminology of 'the digital'. We argue that there are components, already present in the GPN framework that can be explored to help reconceptualize the role of the digital in more fruitful ways. Second, following on from this argument, we draw on a literature analysis to highlight how the three key conceptual categories of GPNs - embeddedness, value, and power can better integrate the digital. Third, to expand understanding and demonstrate how 
these reconceptualizations can be employed in practice, we turn to an empirical case study of the role of the digital in networks of Rwandan tea production.

\section{'The digital' and GPN frameworks}

With growing access to ICTs in the world - and the increasing codification and digitalization of production - data, assets, and information flows have become key elements of production across all economic sectors. A growth in digital information flows (whether the digitization of previously analogue information, the codification of new information, or the emergence of new digital services) is driven by the demands of more granular financial and managerial control, the ability to improve production and the need for more rapid innovation (Malecki and Moriset 2007). Digital assets and information flows can play many roles, but frequently support interfirm production relationships, planning, and coordination; they also expedite more granular and rapid knowledge of production processes and customer behaviour patterns (Castells 2000; Chen 2002). Thus, as digital resources and ICTs become more central to production, we need to understand better their impacts on production networks. Our goal in this article is to fill this gap and to provide clearer theoretical directions as a first step towards systematically analysing global production in an increasingly digital world.

We use the notion of 'the digital' in this article to define the constellation of digital ICTs, connectivity, infrastructure, data and new digital resources that are increasingly crucial in all aspects of the economy. This idea of 'the digital' is built around Berry's (2015) call for a 'post-digital' analysis. That is, an analysis where ICT, information flows and data are increasingly not a 'virtual' add-on to the real world but entwined in everyday economic activities. He (Berry 2015: 2-3) notes:

The world is transitioning from analogue, structured in most part by the physicality of destination, to the digital. A new industrial internet is emerging, a computational, real-time streaming ecology that is reconfigured in terms of digital flows, fluidities and movement. ... This also signals a move away from a previous 'digital' era that was tangential to the capitalist economy, but nonetheless facilitated many economic growth regimes associated with it, such as ICT, finance-led and so forth. Instead we are entering a post-digital world in which the digital has become completely bound up with and constitutive of everyday life and the so-called digital economy.

As Berry notes, analysis of the digital needs to move beyond the rather static analysis of digital ICTs and the digitization of certain flows: rather, we are interested in making a wider socio-technical analysis that emerges from new digital technologies, connectivity, services and ICTs, as well as the increasingly intense and dynamic information flows and the new assets they facilitate.

While the digital has not been part of the core focus of GPN analysis, there are many mentions of its importance in supporting the globalization of production (Dicken 2011). 
More specifically, as theorized in the seminal paper that outlines the GPN framework, ICTs are discussed as a crosscutting element.

We exclude 'technology' as a separate category. Instead, ICT is rather seen as an inherent element of GPNs, underlying the development and maintenance of network connections. Technology, as one of globalization's drivers, influences the processes of value creation in different places, as well as transforming the means by which power is exercised. Additionally, it affects the agents' possibilities of embedding in, and disembedding from, particular networks and territories.

This quote by Henderson et al. (2002: 447) hints at a variety of directions for considering the role of the digital - there are potential directions to exploring the links between the digital and infrastructure, value and power that might be expanded. GPN approaches often focus on the concept of embeddedness - that is, understanding the coupling between networks of global production and the diverse locations within which production networks are grounded (Coe et al. 2004, 2008; Hess 2004). As detailed in the next section, the focus on embeddedness has often led to the digital becoming a background element, an infrastructure that supports non-territorial forms of network embeddedness. We argue that while embeddedness can provide insights into the digital (for example, Wrigley and Currah 2006), it has insufficient breadth to represent fully the growing and dynamic role that the digital is playing in production, in economic relations of firms in GPNs, and ultimately in development.

Using the GPN framework offers significant advances for explaining aspects of firm relations, loci of power and geographies of production, and provides a sophisticated understanding of the global fragmentation of work. Thus, finding richer ways of conceptualizing the digital in the GPN framework is liable to feed into better understandings of relationships and power, and consequently the formulation of more contextually appropriate policy around global production.

\section{Exploring GPN models}

To build a clearer understanding of the digital in GPNs, we explore the three main 'conceptual categories' of the GPN framework - embeddedness, value, and power. The success of the GPN framework owes much to the way that the conceptual categories have been coherently integrated into the framework. At the same time, they sit uneasily and at times draw on diverse ontologies (Sunley 2008). By detailing these diverse ideas, our goal is to consider the different components that make up GPNs. We will later use these components to build a framework to explore systematically the effects of digitalization in GPNs.

We particularly draw here on early GPN literature that introduces key concepts and categories, work that still provides the most substantial theorization of the GPN framework (Dicken et al. 2001; Henderson et al. 2002; Hess 2004). Recent academic contributions, while preserving underlying concepts, have tended to focus particularly 
on the causal drivers of production networks (Coe and Yeung 2015). For instance, cost reduction, firm capabilities, labour power, firm entry barriers and financial discipline have been articulated as important shapers of firm strategies that influence production networks (Barrientos et al. 2011; Coe and Yeung 2015; Mahutga 2012). Our approach is complementary, in that studies of the digital explore how these 'causal drivers' are operationalized in global production networks (namely the ways in which digital technologies are increasingly important in supporting cost reduction, financial oversight and the restructuring of labour in GPNs). However, in the spirit of older GPN work, we also argue that there is a need to consider less deterministic viewpoints. Active strategies can be negotiated, resisted or avoided (Ouma 2010), and in terms of the digital this can be in unexpected spillover effects, path dependency of digital artefacts and appropriation: this means that actual outcomes often differ significantly from those that the economic actors with agency intended.

\section{Embeddedness}

A core element of the GPN framework is the 'embeddedness' of economic relations. The utility of 'embeddedness' is that it allows for an exploration of the ways that actors are orientated by socio-institutional influences through relations within localities, production networks or from firm origins.

As Granovetter (1985) first outlined in his seminal paper on the topic, economic embeddedness suggests that a number of social and cultural norms underlie all economic transactions. Embeddedness thus grounds economic relations within sociocultural factors rather than them occurring in some abstract value-free economic space.

Earlier analysis of embeddedness in economic geography has principally explored how local economic exchanges were defined by the trust, norms, and rules, constituted at a local or national level. The GPN framework goes beyond a one-dimensional perspective of embeddedness to explore a variety of other forms of embedded exchanges as outlined by Hess (2004). 'Economic geography has been prone to use what I will call an "overterritorialized" concept of embeddedness by proposing "local" networks and localized social relationships as the spatial, logic of embeddedness, which might result from "spatial fetishization"” (Hess 2004: 174). Drawing on such arguments, the GPN framework expands the definitions of embeddedness to consider what has been referred to as 'network embeddedness', namely the 'connections between network members regardless of their country of origin or local anchoring in particular places. It is most notably the "architecture", durability and stability of these relations, both formal and informal, which determines the agents' individual network embeddedness' (Henderson et al. 2002: 443).

Thus, one can think of network embeddedness as a gamut of sectoral norms, rules, professions, and institutions that orientate the activities of firms in global production. An additional category of societal embeddedness is also sometimes used. ${ }^{1}$ This is the culture that firms involved in global production bring from their home country, which continues to influence them as they expand globally (Henderson et al. 2002; Hess 2004). The justification for use of the two/three categories of embeddedness and their 
differentiation (territorial, network/societal) is never fully justified, but there is a nod to Castells and his concept of 'space of places' and 'space of flows' to explore the coupling between durable territorial norms and those in network relations (Castells 2000; Henderson et al. 2002).

As mentioned in the previous section, the digital is only elusively present in theorizations of embeddedness. The digital tends to be framed as background infrastructural elements that facilitate network embeddedness. Digital information flows and ICTs are barely mentioned by name, but it can be inferred that the durability of nonterritorialized relations (and consequent embedded exchange) come at least in part from digital infrastructure and networks that enable the durable exchanges in GPNs.

\section{Value}

The notion of 'value' is used to outline the actors and positions within networks where rents (frequently economic ones) are created, enhanced or captured. Two aspects of value are particularly influenced by the digital. First, the introduction and expansion of new digital information flows, services, and networks may alter the economic value distribution within production networks. Second, we are seeing new types of 'digital production network' emerging in areas like online services, knowledge work and web production (Beerepoot and Lambregts 2015; Lehdonvirta et al. 2015). 'Digital production networks' are often still at nascent states, so significant research needs to be done to understand the concept of value in such networks (Löfgren 2003; Terranova 2000). We therefore focus only on the former category in this article, a focus that will be most relevant for those exploring the digital in existing GPNs.

In terms of value, GPN models often closely align with global commodity chain (GCC) and global value chain (GVC) approaches (Coe and Yeung 2015). In particular, chain based models have been effective in exploring the distribution and governance of value in interconnected networks of production. In earlier commodity chain literature, the notion of value was more closely aligned with surplus value that emerged out of differences between labour costs of commodity production and the exchange value of those goods. Forms of network governance (and consequently the distribution of value in networks) were articulated to emerge mainly as a result of innate characteristics of a particular production sector - that is to say that value distribution principally emerged from the products, production requirements or sectoral structures within which production existed (Gereffi 1994). More recent value chain research has probed networks at a more granular level, focusing more on aspects of value that emerge from economic rents, and those activities such as innovation, branding and business models that allow firms to charge an economic premium on goods and services. Value chain models highlight the increasingly sophisticated ways that production is organized in networks (such as by modularization of production and standardization), even as the products and processes in these chains have become ever more complex and personalized (Gereffi et al. 2005; Sturgeon 2002). This more recent work has argued that value distribution is not only an outcome of sectoral properties and labour, but can be enhanced as value chains are designed, managed and improved with appropriate modularization, quality 
control or institutional oversight (Kaplinsky and Morris 2001). This more recent value chain research then opens up a more purposive way of thinking about value, where ICTs and digital information flows can be one way of reconfiguring and shaping network relations and value distribution.

A number of studies have explored the effects that the digital can play in supporting production structures and exchange. Notably, work during the emergence of the internet (Benjamin and Wigand 1995; Gereffi 2001) discussed the potential for digital networks to rework production processes and chains. In particular, Gereffi outlined some of the implications of the internet that might transform network governance: new online channels might allow producers to capture more value at the expense of intermediaries; interfirm digital services could reduce chain management and transaction costs; and the ability for personalization could lead to profits becoming centred on the ability for customer personalization. However, this literature drew on limited empirical evidence from a time when the digital services and ICT were still diffusing and tended to reflect optimistic visions of new digital networks. We argue that there are also some theoretical weaknesses in the way that value and the digital have been considered. There is a tendency to dwell on value creation and enhancement over value capture - that is there is more discussion about the new products, services or value-added that the digital drives, but less about to whom (and where) such surpluses accrue (Coe and Yeung 2015). There is also a risk that research on the digital and GPN will focus on value only economic rents and the ways in which the digital transforms business without understanding how digital technology may also affect the ways of producing surplus value. It is well known that digital technologies not only transform business but in the process also transform work patterns and divisions of labour (Castells 2000), so it is important to consider these impacts in the analysis.

Thus, we only have a partial picture of the impacts of digital technologies on the distribution of value. Will the promised improvement be accessible to all actors in GPNs? Where in production networks will the 'value' from the digital be captured? How will the digital also affect the division of labour and structures of work?

\section{Power}

In their seminal work outlining the GPN framework, Henderson et al. (2002) see power as exercised in three different ways - corporate (firms), institutional (state, global institutions) and collective (unions, NGOs), all which imply wilful agent-led activities with little room left to conceptualize the digital. However, an analysis of how actornetwork theory (ANT) has been integrated into the GPN framework can serve as a starting point to think about the power and the digital.

The GPN framework is strongly influenced by ANT thinking of networks constantly in the making, and ANT ideas strongly cohere with case studies of global production networks as often complex and reconfigurable (Chen 2002; Lüthje 2002). The ANT notion of the duality of actors and networks is key; it problematizes actors, who from ANT perspectives are considered to be constituted by networks of other actors (Latour 1999). Duality is powerful in that it provides a theoretical basis for the 
GPN framework to move beyond linear explorations of production relations as exemplified by GCC/GVC approaches. If each actor in the value chain is constituted by a whole gamut of networks relations and actors, one also needs to consider these constituting actor-networks (Coe et al. 2008). Thus ANT perspectives highlight more distributed sources of power where global production is shaped by interactions within localities and networks, and allows traversing between different scales of economic interactions.

However, without the inclusion of the 'non-human' as an actor with agency, the outline sketched out above only presents a partial picture of ANT and power. Inclusion of non-human actors prompts us to consider the role that objectified resources (including digital objects and information flows) play in influencing networks, and how these non-humans influence activity (Latour 2005). GPN literature has referred to non-human actors in relation to power previously, particularly in early theoretical work (Dicken et al. 2001; Yeung 2003). 'The implication [of ANT] for understanding the development of the global economy is that analysts need to recognize "agency" as an "effect generated by a network of heterogeneous, interacting materials" in which the non-human plays a critical role in embodying and shaping (often in unexpected ways) action' (Dicken et al. 2001: 102).

However, there appears to be some friction among key architects of the GPN framework. For instance Coe and Yeung (2015) have argued that one of the key differentiators of the GPN framework from simply using ANT on its own, is that the notion of non-human 'agency' should not be integrated within GPN notions of agency and power. ' 'To be clear, GPN1.0 does not adopt ANT wholesale. It does not, for example, confer agency upon non-human objects as ANT does' (Coe and Yeung 2015: 12).

While we are sympathetic to the notion of 'agency' being a problematic term with which to explain the role of objects in guiding and constraining networks, this should not lead to a partial use of ANT in GPN analysis. The marginalization of ANT is detrimental to understanding how the digital relates to power and, as the growing use of ANT in neighbouring fields such as information systems and organizational studies shows, ANT can provide new insights on organization (Ciborra et al. 2000; Orlikowski 2010). Since studies in these neighbouring fields have explored digital technologies through the entanglements of objectified structure and social structure, they have attributed a more active role to ICTs, in which the affordances, inscriptions, and constraints of technology can guide, define, or restrain human agency and relationships. These works point towards approaches to power that the GPN framework could also look to integrate.

\section{Summary}

The three conceptual categories and the ways that the digital has been integrated are shown in Table 1. 'Embeddedness' examines the durable relations and norms that guide economic activity, which have their basis in both localities and networks. 'Value' explores the ways that value is created, enhanced, and distributed in networks of firms, and how distribution of value can be improved or changed. 'Power' explores the shifting nature of control in networks, and the multiple scales at which networks act. 
Within all three conceptual categories, we have highlighted deficiencies in conceptualizing the digital. The deficiencies are similar in all three categories: the digital is rarely problematized as a changing, dynamic, and active element in globalized economy. It is either treated as a background element or ignored. The literature review has alluded to some ways in which the digital might be better brought into GPN analysis - as a more foregrounded element in embeddedness, treated more critically in the distribution of value, and as a non-human actant with effects on power structures. Yet, these insights are incomplete and we need clearer illustrations to show how they allow us to analyse the digital better.

Table 1: The three conceptual categories on relations in GPNs

\begin{tabular}{lll}
\hline $\begin{array}{l}\text { Conceptual } \\
\text { category }\end{array}$ & \multicolumn{1}{c}{$\begin{array}{c}\text { Coverage in existing GPN literature } \\
\text { Use in GPN literature }\end{array}$} & \multicolumn{1}{c}{ Incorporating the digital } \\
\hline Embeddedness & $\begin{array}{l}\text { Move beyond 'overterritorialized' } \\
\text { focus to explore network } \\
\text { embeddedness }\end{array}$ & $\begin{array}{l}\text { The digital as underlying durable } \\
\text { non-spatial interactions }\end{array}$ \\
Value & $\begin{array}{l}\text { Value distribution and the } \\
\text { network mechanisms which } \\
\text { support changes in distribution }\end{array}$ & $\begin{array}{l}\text { The digital strengthening net- } \\
\text { work exchange and monitoring } \\
\text { (but rarely in core GPN work) }\end{array}$ \\
& $\begin{array}{l}\text { Power mainly seen in terms of } \\
\text { agency, but ANT offers ways of } \\
\text { exploring complex networks in flux }\end{array}$ & Low coverage in GPN literature \\
\hline
\end{tabular}

\section{Exploring the digital in GPNs}

\section{Approach}

We present a set of illustrations, as extracts, to expand on how we can better integrate the digital into the core categories of the GPN framework. The goal here is to add some clear empirical examples of digital activity to support the substantial theoretical discussion, and to help expand on some of the key insights made.

To explore links between GPNs and the digital, we discuss research undertaken in the GPNs of tea production with a particular focus on Rwandan production. Our case selection here originates from our interest in the integration of digital technologies closer to producers, particularly more marginal groups in the Global South. In contexts of the digital, this case also lucidly illustrates that even in long-established commodity sectors largely characterized by material goods, we are seeing the growing importance of 'the digital' in reshaping the sector.

In recent years, Rwanda has been undergoing significant transformation in its digital connectivity, with the construction of a series of submarine fibre-optic cables linking the region to the rest of the world (before 2009, the region was entirely dependent on satellite connectivity) (Foster and Graham 2015a). In addition, the growth of ICT and mobile phone use in the region means that even low-income producers may be able to 
access digital information flows (Foster and Heeks 2013). The goal here is to illustrate some of the impacts of the digital on tea production networks: in particular, we need to focus on how the digital might have affect the ways in which Rwandan actors link into these networks using the core categories discussed previously.

\section{Introducing Rwandan tea production}

In the last decade, Rwandan tea farmers became increasingly interconnected into the global production of tea. This change has notably occurred as part of wider trends of developing country tea production moving away from state control in government tea boards towards private sector development. Consequently, tea operations in Rwanda such as tea processing ${ }^{3}$ and transportation are now run by private firms, including buyouts by large tea multinationals overseen by a commercially orientated regulator - the National Agricultural Export Board (NAEB).

Privatization in Rwanda has been strongly supported by the political leadership, most notably by president-cum-CEO Kagame's push for economic growth through private sector development, a drive that has led to the country being dubbed 'Rwanda Inc.' (Crisafulli and Redmond 2012). Nevertheless, given that Rwanda continues to bear the scars of recent conflicts, it is still necessary to ensure stability in the country. In industry, ensuring stability results in political actors having control of key firms in the economy, what Booth and Golooba-Mutebi (2012) referred to as 'developmental patrimonialism'. Thus, even as the tea sector moves towards privatization, the state still exercises power, mainly indirectly through its influence on key firms and regulators.

\section{Figure 1: Stylized outline of operational links linked to Rwandan tea production}

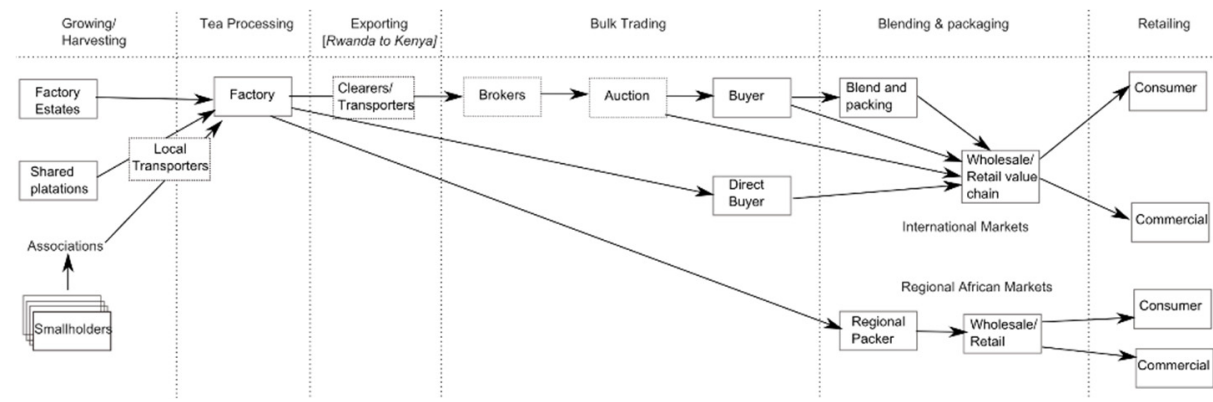

Source: authors' fieldwork.

As Figure 1 shows, tea production in Rwanda is well integrated into global networks of tea distribution. Green tea leaves produced mainly by rural smallholders are sold via cooperative associations to tea factories that undertake preliminary processing. Processed tea then passes through a set of intermediary trading stages (discussed below), which result in large tea firms buying tea in Kenya, then packaging and transporting it to international markets. Some Rwandan tea is sold directly to retailers (as shown in the middle of the diagram), but the majority still tends to be sold via an intermediary auction in Mombasa, Kenya. 
As with other agricultural sectors, tea is moving away from being a generic commodity and, in Rwanda, varying types and marks of tea are targeting a range of customers. Some tea producers are contributing to high value-added, high quality teas bought by boutique tea firms abroad, but the majority is still bought by large tea retailers and used as part of tea blends ${ }^{4}$ for commercial retailing. An increasing volume is also sold (as we show in the bottom-right of the diagram) to regional or emerging market consumers in locations such as Pakistan, Central Asia, and the Middle East (Africa Tea Brokers 2015).

A key finding of our research in Rwanda was that private sector development had led to only limited modernization of tea processing machinery or improved tea-farming practices. However, the growth and introduction of information technologies and digital connectivity have been significant. All tea processors interviewed had internet connectivity. This is surprising given the remote location of some of the facilities, ${ }^{5}$ which in some cases required the construction of towers within facility grounds in order to facilitate wireless connectivity. Equally, many elements of the production process, such as data on green tea quantities from farmers, processed tea batches, and tea quality, have been codified, digitized and shared to allow improved management and traceability of tea goods as discussed below.

\section{Embeddedness}

In the Rwandan tea sector we explored how tea firms were integrating into international tea production networks (and consequently the role of the digital in influencing norms, rules, and institutions in Rwanda). A key finding in this analysis was that the integration of Rwandan firms into international production did not entail a consistent set of requirements or influences locally. Rather, Rwandan firms were making diverse, multiple and different economic linkages, each with its own characteristics of activity and requirements.

Two illustrative network linkages in Rwandan tea highlight these contrasting norms and requirements of different networks. One was around auction selling of tea (the upper path from left to right in Figure 1), the other around direct selling of tea (the path in Figure 1 passing through the 'direct buyer'). These different networks had distinctive institutions and approaches to trust. Auction selling is a many-to-one exchange from producer to retailer where economic relations revolve around the rules, norms, and institutions that have emerged over a long time in the region to ensure trust in auction exchanges. Direct selling networks tend to be a one-to-one and are grounded in direct high trust firm-to-firm relations. Tea processors in Rwanda may build relations in one or both of these networks (dependent on tea quality, and demand), and this can lead to contradictions. For example, direct selling networks push integrated economic relationships that may reduce local firms and policymakers' ability to dictate production (for example, less transparent pricing, less opacity in exchanges). In contrast, as firms in Rwanda have looked to value-addition of tea (fair trade, packaged or new types of tea), the norms of the auction network have been slow to adapt to these changes (for example, respondents commented on finding it difficult to integrate certifications into auction norms). 
The digital also plays more than just an underlying infrastructural role as shown in Figure 2. Auction selling was characterized by 'digital fragmentation', fragmented and actor-initiated digital exchanges (for example, through email exchanges, payment services, looking up online catalogues, spreadsheet updating). In contrast, direct selling was characterized by 'digital integration', the automation of a whole slew of digital parameters as part of integrated tracking and monitoring of production, transport and goods. These two modes of digitally mediated exchange underlie the economic exchange and had significant effects on the way specific Rwandan firms were interacting. Digital fragmentation allowed firms in Rwanda more leeway to integrate the requirements of international production within local norms. By contrast, digital integration acted in many ways like a bulldozer. Some Rwandan tea producers were in the process of integrating with software and systems defined by parent tea companies and the requirements of these systems were beginning to orientate many new elements of activity, so reducing the ability for any local adaptation of activities.

\section{Figure 2: Simplified and generalized schematic of key digital data flows in the} production of Rwandan tea

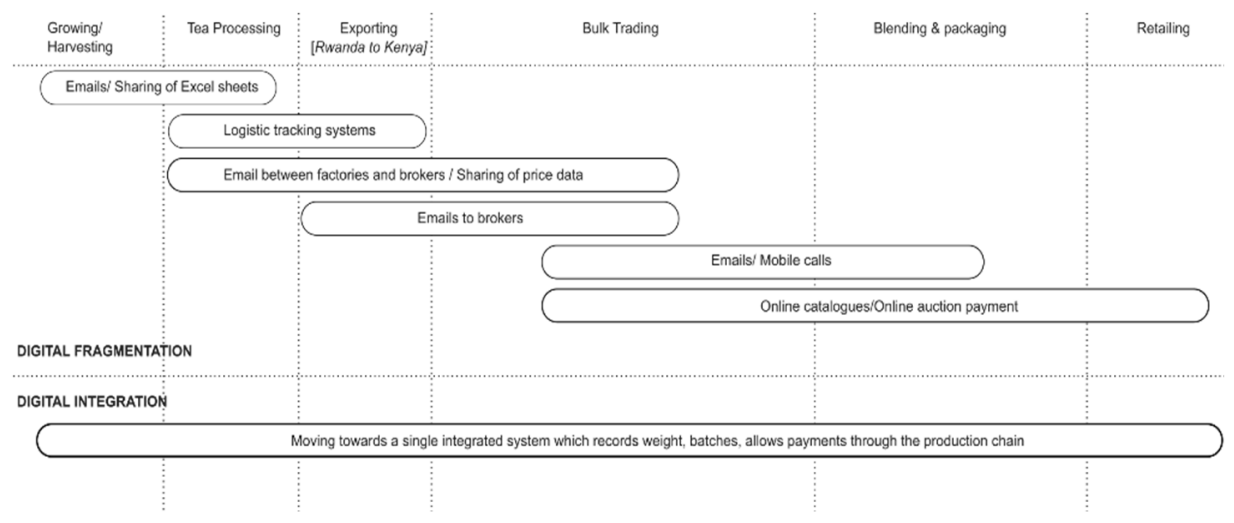

Source: authors' fieldwork.

In sum, this illustration highlights that the GPN concept of network embeddedness - that set of durable interactions that are not territorially mediated - are not necessarily singularly coherent. Expanding connectivity enables a diverse range of networked interactions that are liable to lead to a range of different durable network relations. Moreover, the digital infrastructure itself that facilitated network interactions was important, in the ways that platforms and technology orientated the types of norms and activities that define embeddedness.

\section{Value}

As outlined previously, achieving standards and sufficient quality of goods is an increasingly important element of agricultural production, and is entwined with the economic value of those goods (Gwynne 2006; Ouma 2010). In Rwandan tea, one way 
in which standardization and quality are pushed is that exchange was increasingly mediated via digital technologies as a means of allowing exchange to be monitored.

Rwandan tea processors now operate 'weighbridges', which enable them to verify and digitally integrate the weight of the green tea leaves that arrive at the processing facilities from farmers' cooperatives (groups of smallholder tea farmers use cooperative associations to simplify transport and payment). Some tea processing plants have also adopted more advanced field weighing where the weight of the tea leaves harvested from smallholders are integrated into the tea processor's information systems.

Intuitively, such digital devices, which simplify the complexity of green leaf weighing and payments, appear to offer reduced corruption and modernization of tea production. For instance, with field weighing, one large tea cooperative association's chairperson whose farmers had recently begun to use these systems outlined the benefits. 'With the old system, we used to record slight differences in what has been weighed in the fields and what has been weighed at the factory [tea processor] but today it is all the same. The new system is much better and the beneficiaries never stop commending its benefits.' However, digging deeper, one increasingly sees risks with this technology. The new digital systems benefit some, but for others they were exclusionary. For example, one leader of a smaller cooperative association made up of very low income farmers described the impact that digital weighing technologies have had on her cooperative:

Before, we [the cooperative association] used to weigh green leaves for ourselves as a coop. But today, the weighing work is done by the factory and they use electronic balances [field weighing] ... the coop is just there doing nothing ... the bonds which once connected farmers to the coop have now shifted to the factory therefore, and as [a] result, farmers find themselves more directed to the factory than to the cooperative.

Thus, technology mediated exchange has not benefited all stakeholders equally. It may have a longer-term exclusionary effect on certain smallholder farmers by excluding tea cooperative associations. This is important as cooperative associations have traditionally been an important source of advocacy for the rights of smaller growers and pluckers in the tea sector.

In sum, although changing digitally mediated network governance may give GPNs more control and value, only some actors, namely the larger firms that can achieve savings and greater efficiency, are able to capture these benefits. There are also indications that, beyond the economic benefits, the digital is having an impact on the division of labour and is negatively restructuring value and beneficial relationships, as well as increasing the precarity of some actors.

\section{Power}

Tea production in Rwanda occurs through networks of actors (tea pluckers, smallholder farmers, tea processors, tea processor owners, cooperative associations, NGOs, and so on). An exploration from ANT perspectives would also include non-human actants $^{6}$ in 
the actor network. In Rwanda, we can identify a number of digital technologies as key actants in shaping networks - smartphones, farmer databases, digital weighing machines, and mobile money - that had been brought into and oriented networks. Following core ANT approaches, we discuss how the quite different ambitions and activities of different actors and firms (profit, farmer livelihoods, national development goals, political goals, and donor goals) are aligned and how alignment occurs, particularly with respect to the role of the digital.

In interviews, managers of commercial tea processors were often frustrated at the lack of impetus in the sector in transitioning to become commercially oriented. There were many complaints about the inefficiencies of smallholders, cooperatives, and government. For these commercial managers, the recruitment of digital technology into discourses was central to articulating a vision for the commercial future of the sector, and an important element of mobilization for driving towards a fully a commercial sector. For example, take the words of one general manager discussing future technology developments.

We are also adding another sort of information component to that system, where a farmer gets his pay slip on his mobile phone in addition to the green leaf weighing slip. In the future we look at setting up some kind of a platform where they can send users a USSD code and communicate with the factory and access the database there, look at their account and things like that.

Here the digital (USSD, mobile phones, databases) are recruited into the network as a tool to envision and describe future goals and hopes. Not only do these digital actants solidify the visions of the manager, but suggest inevitability, acting for certain visions as a mobilizing and stabilizing force.

Second, where actor networks were more integrated, we increasingly saw how norms and rules of production became materialized through the act of inscription (Latour 2005). For digital technology, a particularly studied element of inscription has been in how the embedding of processes into systems, software, or algorithms stabilize certain processes or rules (Spinuzzi 2008). Such digital technologies are important when they circulate because they provide a means for these processes and rules to spread. One example of inscription and circulation in the Rwandan case was how digital field weighing devices had been integrated with information systems. Integration was undertaken in Rwanda through transferring software and technology from Kenya, where it had been custom designed and deployed for the local Kenyan context. The power of a large umbrella institution (called Kenya Tea Development Agency KTDA), which trades, controls and monitors much of the tea production on behalf of smallholders, defines much of Kenya's tea sector. This is important because, when field weighing integration was transferred from Kenya to Rwanda, the structures inscribed in the technology in Kenya became problematic in Rwanda.

In Kenya, the software was designed to enable the KTDA to manage its tea production from the top down. Transferred to Rwanda, this system favoured large tea firms, for it also allowed them to input and access information from the top down. 
However, in Rwanda, where more independent and active cooperatives interact with private tea factories, the software was not set up to afford access to smaller producers and cooperatives. Given that these systems were already well established, tested and functionally working from the perception of the large tea firms, there has been a reluctance to modify the software and its functions.

In sum, from an ANT perspective, the digital is highly entwined with the actors involved in tea. Digital technologies may be recruited into networks to exert control, as in the illustration above with recruitment of digital actants into articulations of technology. Because circulations of digital technologies also had the power to change actor networks, to change the way in which norms became inscribed in the digital, they could also therefore affect the stability of actor networks.

\title{
Discussion
}

Table 2 details the three conceptual categories of GPNs. Drawing on our empirical study, the second column summarizes how the digital might be better integrated into GPN analysis.

Table 2: The GPN framework and role of the digital

\section{Conceptual category \\ Suggested expansion to better conceptualize the digital}

\begin{abstract}
Embeddedness Network diversity
Problematizing network embeddedness - diversity of digital networks
\end{abstract}

\section{Digital (infra)structure}

The digital as an infrastructure in shaping network embeddedness

Value Digitally-driven shifts in governance and value

Critical approach to new value distribution enabled by digital exclusionary, spillover effects, who are the winners and losers?

Power $\quad$ ANT - Non-human actants

Considering a central role of the digital in the constitution of actor-networks

\section{ANT - Translation processes}

Focus on translation processes to better explore power and circulation

The concept of embeddedness is important for GPN analysis in exploring the coupling between durable economic relations in networks and territories. However, as illustrated in the Rwandan case, there are questions of how embeddedness as a concept is best used. With the digital becoming more prevalent, there is the possibility of a range of diverse network relations through which durable interactions occur (particularly as digital technologies make non-territorial networks easier to maintain).

As we highlighted previously, Castells's 'space of flows' and 'space of places' influenced notions of network embeddedness; our observations are in line with some 
of the critiques made of Castells's concepts in the last decade. 'It seems clear today that the radical dichotomy of the space of flows and the space of places suggested in the late 1980s ... has dissolved. Now the connections between the two types of space are much more complex and flexible' (Stalder 2006: 152). In this quote, Stalder highlights that the simplistic categories of 'network' and 'place' may need to be better refined. ${ }^{7}$ This critique serves as an insight into a GPN analysis of 'network' and 'territorial' embeddedness that mirrors Castells's dichotomy. It can be problematic when network embeddedness becomes a catchall for a whole slew of durable relations that are not necessarily coherent or consistent. Recent work by Coe and Yeung (2015) on the varying forms of GPN aggregation and Gereffi's discussions of the importance of contrasting South-South value chains (Gereffi 2014; Gereffi and Lee 2012) allude to this increasingly problematic reification of network embeddedness.

We also saw how the digital infrastructure itself was a key element in orientating embeddedness. Economic relations were embedded in socio-cultural norms, but the forms of digital infrastructure (namely digital integration and digital fragmentation in the Rwandan case) also influenced network embeddedness. Further research drawing on the information-infrastructure literature could be valuable to embeddedness. This includes exploring forms of ICT, applications, codes, standards and algorithms that can themselves be 'invisible mediators of action' (Bowker and Star 2000).

Where the digital has been associated with shifting distributions of value, existing literature has largely taken an optimistic view focusing on the creation and enhancement of economic rent through new efficiencies and services, but without sufficient empirical support. As outlined in the Rwandan case, new digital elements in network governance can lead to new efficiencies but these gains may be captured outside the places where these efficiencies occur. We also highlighted that the digital had knockon effects of the division of labour and the way digital information systems has led to diminished responsibilities for tea cooperatives in the Rwandan case. A handful of other recent cases have explored the effects of the digital on production in such settings, and they highlight similar impacts of the digital (Graham 2014; Murphy and Carmody 2015): first it can reduce flexibility by sidelining important alliances of producers as opposed to removing intermediaries. Second, due to the requirements of digital systems, integration of digital services may be more exclusionary. Third, digital resources that solve a problem are liable to result in gains far away in the value chain. Thus, the key to a more critical approach is to reflect on how the digital affects wider chain relations. It is important to explore both intended and unintended effects, to scrutinize how the digital is reconfiguring the division of labour, and to find out where value is actually captured in networks. We thus need to pose questions about who benefits, and who does not (in practice) from the digital, and how digital mediated exchanges reconfigure power and relationships in GPNs (Graham 2014).

By bringing non-humans actants more explicitly into the GPN analysis of economic relations, we have been able to explore diverse perspectives on power. Current GPN theorizations use ANT to integrate the analytical concept of 'actor-network', but this neglects the core of ANT thinking underplaying the ways that ANT theorizes power. Our critique here mirrors Law's (1999) disappointment at the way other fields have 
appropriated ideas from ANT, thus folding a rich set of ideas into a single concept, the 'actor-network'. 'Like some kind of monster, the term "actor-network" grew, and it started, like a theoretical cuckoo, to throw the other terms out of the nest. Which, with the privilege of hindsight, seems both significant and ominous' (Law 1999: 5).

In our illustrations we have shown how ANT can provide a useful lens for the bringing into being of actors, norms, and networks, through close analysis of the processes of translation - the ways that networks of both human and non-humans are recruited, mobilized and cohered in networks (Murdoch 1998). Translation is at the very core of ANT exploration of understanding how some actors are able to exercise power over others (Law 1999). For the digital, exploring translation processes is a matter of analysing the alliances and agreements that shape certain digital technologies, ultimately offering us the potential to understand power and the circulation of ideas in networks.

\section{Reconsidering the digital}

This work aligns with a growing literature exploring the less visible processes or artefacts involved in production networks (such as quality, standards and logistics) (Coe and Hess 2013, Ouma 2010, Ponte and Gibbon 2005). Because these elements are 'far less tangible and visible in their imprints on the networks' (Coe and Yeung 2015: 54), they have been less studied in GPN work than explorations of agency and firms. Clearer theorizations are integral to integrating these understudied facets of production networks.

Through a theoretical examination, in this article, we have explored the role of the digital in the three conceptual categories of GPNs - embeddedness, value, and power. Embeddedness explores the underlying durable norms in territories and networks that shape production relations, where the digital has been seen as a background element that enables durable interactions. We have linked value to the network distribution of rents or surpluses and explored the more overt mechanisms used to support exchange. Here the digital has been seen in a mainly positive light in supporting networked transformation through processes such as disintermediation. Integrating the digital into the category of power prompted us to look towards actor-network theory, but there has been barely any substantive use of actor-network theory in studying the digital in GPN literature.

Drawing on empirical illustrations, we have highlighted how the digital could better be conceptualized in GPNs. For embeddedness, complicating network embeddedness to incorporate the complexity of digital networks is important, as is a consideration of the role that the digital plays in shaping durable economic relations. For value, the existing literature suggests a tendency to lean towards idealized visions of the digital and its effect on value. A more critical approach to analysing how the digital influences network exchanges could improve understanding of which actors gain (or not) from the digital, and how it affects the labour process. For actor-network theory, more consideration of non-humans within actor networks is a vital starting point to consider better the co-constitution of networks and the role of the digital. Essential to analysis is to position the network as a process, and to explore the translation processes by which actor networks come into being. 
Figure 3 illustrates these recommendations by superimposing our exploration of the digital onto the original GPN model of Henderson et al. (2002). We still take the digital to be a crosscutting element of GPNs, but then look to explore how the digital influences the three conceptual categories outlined in key GPN work. Empirical work suggests that all three elements overlap to some degree in that they all try to integrate more complex and materially rich perspectives of the digital in GPNs.

Although we have specifically focused on the broader GPN position, which fits our empirical interest, our conclusions can also be useful for the wider family of models in economic geography that adopt relational frameworks (such as GVC/GCC research).

\section{Figure 3: Adapting the GPN framework to analyse the role of the digital}

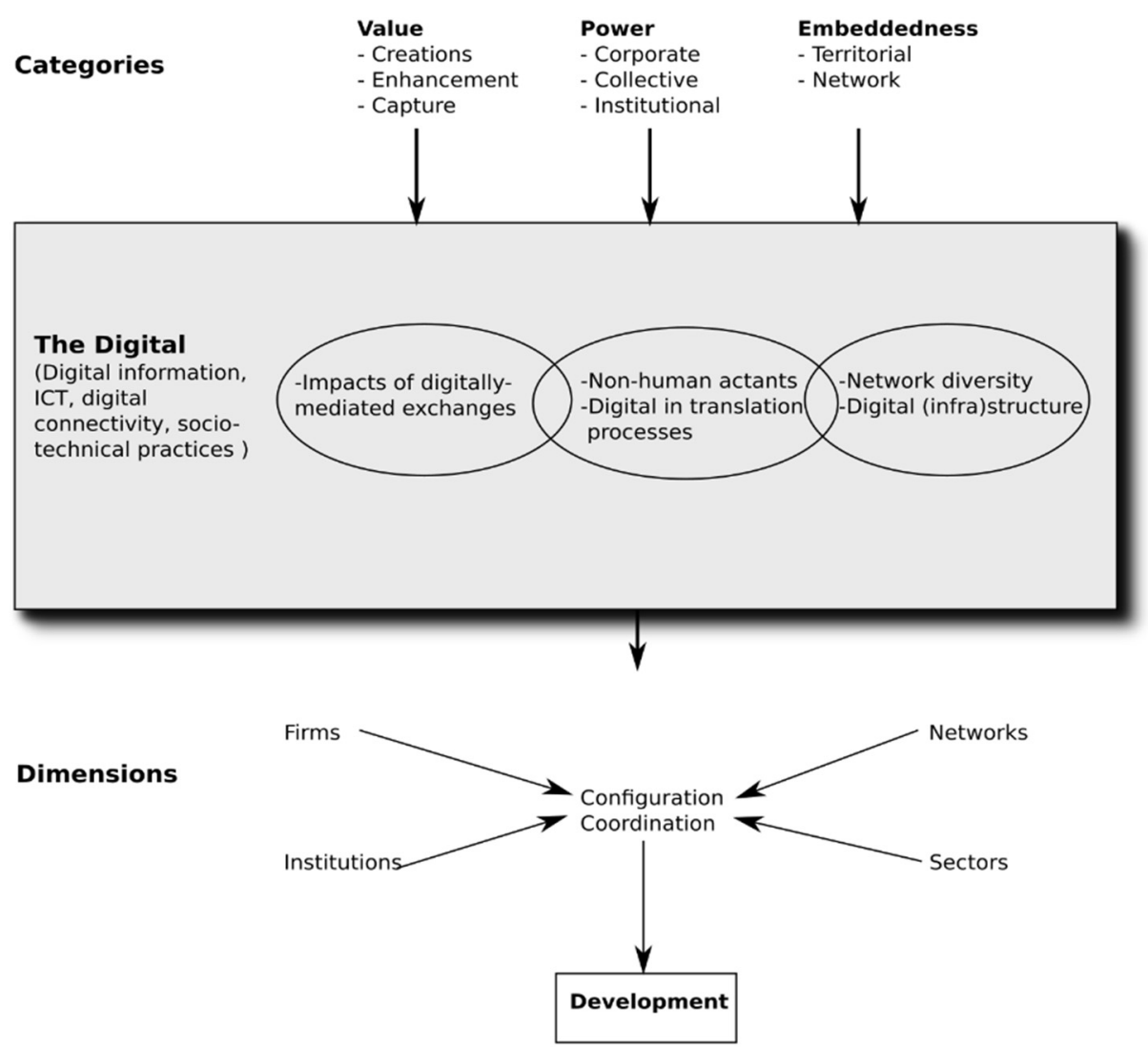

Adapted from original framework by Henderson et al. (2000).

In sum, we see this reconsideration of the digital in GPNs as a starting point. It allows us to make richer theorizations of the digital that complement perspectives of global production at multiple scales and in constant interplay between networks and territories. The directions and empirical approaches outlined offer clearer directions for future studies to think more deeply about the growing role of the digital in economic production both theoretically and empirically. 


\section{Christopher Foster and Mark Graham}

\section{Acknowledgements}

This article draws on research funded by the UK Economic and Social Research Council (ESRC) and the Department for International Development (DFID) (Grant reference: RES-167-25-0701). The authors would like to thank Laura Mann, Tim Waema and Charles Katua whose inputs to this research project were valuable to the article. We also appreciate the critical comments and suggestions on earlier drafts from Shamel Azmeh and the two anonymous reviewers.

\section{Notes}

1. In GPN frameworks societal embeddedness is sometimes amalgamated with network embeddedness, as a specific example of network embeddedness.

2. It should be noted that such discussions mirror the debates that have raged among STS scholars for many years.

3. Tea includes a processing stage post-harvest that converts perishable green tea leaves to unpackaged 'made tea' for later packaging, blending and/or export

4. Blends combine tea produced in multiple locations into a single product to maintain a consistency of taste for the consumer even as tea quality from a particular location varies.

5. Tea leaves have short lifespans once plucked, so factories are located close to clusters of teagrowers often in remote highland locations with suitable soils.

6. We keep actor-network terminology to a minimum in this section to make it accessible to non-specialists, but include some notions as italicized.

7. We acknowledge that embeddedness at a higher level may still be useful in a very structural analysis that argues for the dominance of globalization and the way that globalized norms crowd out local practices and norms. However, this forms only one way that embeddedness might be used to explore global production.

\section{References}

Africa Tea Brokers (2015) 'Africa tea brokers', online auction data, available at: www.atbltd.com/Docs/graph.

Barrientos, S., G. Gereffi and A. Rossi (2011) 'Economic and social upgrading in global production networks: a new paradigm for a changing world', International Labour Review, 150 (3-4), 319-40, doi: 10.1111/j.1564-913X.2011.00119.x.

Beerepoot, N. and B. Lambregts (2015) Competition in online job marketplaces: towards a global labour market for outsourcing services? Global Networks, 15 (2), 236-55, doi: 10.1111/ glob.12051.

Benjamin, R. and R. Wigand (1995) 'Electronic markets and virtual value chains on the information superhighway', Sloan Management Review, 36 (2), 62-72, available at: http://goo.gl/19Q6EJ.

Berry, D. (2015) Critical theory and the digital, London: Bloomsbury Academic.

Booth, D. and F. Golooba-Mutebi (2012) Developmental patrimonialism? The case of Rwanda, African Affairs, 111 (444), 379-403, doi: 10.1093/afraf/ads026.

Bowker, G. C. and S. L. Star (2000) 'Invisible mediators of action: classification and the ubiquity of standards', Mind, Culture, and Activity, 7 (1-2), 147-63, doi: 10.1080/10749039.2000.9677652.

Castells, M. (2000) The rise of the network society, Oxford: Blackwell.

Chen, S.-H. (2002) 'Global production networks and information technology: the case of Taiwan', Industry and Innovation, 9 (3), 249-65, doi: 10.1080/1366271022000034480.

Ciborra, C., K. Braa and A. Cordella (2000) From control to drift: the dynamics of global information infrastructures, Oxford: Oxford University Press. 
Coe, N. M. and M. Hess (2013) 'Economic and social upgrading in global logistics', Capturing the gains working paper, 2013/38, University of Manchester, available at: www.capturingthe gains.org/pdf/ctg-wp-2013-38.pdf.

Coe, N. M. and H.W. Yeung (2015) Global production networks: theorizing economic development in an interconnected world, Oxford: Oxford University Press.

Coe, N. M., M. Hess, H. W. Yeung, P. Dicken and J. Henderson (2004) “'Globalizing” regional development: a global production networks perspective', Transactions of the Institute of British Geographers, 29 (4), 468-84, doi: 10.1111/j.0020-2754.2004.00142.x.

Coe, N. M., P. Dicken and M. Hess (2008) 'Global production networks: realizing the potential', Journal of Economic Geography, 8 (3), 271-95, doi: 10.1093/jeg/lbn002.

Crisafulli, P. and A. Redmond (2012) Rwanda, Inc.: how a devastated nation became an economic model for the developing world, New York: Macmillan.

Dicken, P. (2011) Global shift: transforming the world economy, 6th edition, London: Guildford Press.

Dicken, P., P. F. Kelly, K. Olds and H. W. Yeung (2001) 'Chains and networks, territories and scales: towards a relational framework for analysing the global economy', Global Networks, 1 (2), 89-112, doi: 10.1111/1471-0374.00007.

Foster, C. G. and M. Graham (2015a) 'From connectivity to digital contestations: the effects of fibre-optic infrastructure on firms in East Africa', paper presented at Social Implications of Computers Conference (IFIP9.4), Colombo, Sri Lanka, May.

Foster, C. G. and M. Graham (2015b) Connectivity and the tea sector in Rwanda, project report, Oxford Internet Institute, available at: http://cii.oii.ox.ac.uk/tea-report/.

Foster, C. G. and M. Graham (2015c) The internet and tourism in Rwanda, project report, Oxford Internet Institute, available at: http://cii.oii.ox.ac.uk/tourism-report/.

Foster, C. G. and R. B. Heeks (2013) 'Innovation and scaling of ICT for the bottom-of-thepyramid', Journal of Information Technology, 28 (4), 296-315, doi: 10.1057/jit.2013.19.

Gereffi, G. (1994) 'The organization of buyer-driven global commodity chains: how US retailers shape overseas production networks', in G. Gereffi and M. Korzeniewicz (eds) Commodity chains and global capitalism, Westport, CT: Praeger, 95-122.

Gereffi, G. (2001) 'Beyond the producer-driven/buyer-driven dichotomy the evolution of global value chains in the internet era', IDS Bulletin, 32 (3), 30-40, doi: 10.1111/j.1759-54 36.2001.mp32003004.x.

Gereffi, G. (2014) 'Global value chains in a post-Washington consensus world', Review of International Political Economy, 21 (1), 9-37, doi: 10.1080/09692290.2012.756414.

Gereffi, G. and J. Lee (2012) 'Why the world suddenly cares about global supply chains', Journal of Supply Chain Management, 48 (3), 24-32, doi: 10.1111/j.1745-493X.2012.03271.x.

Gereffi, G., J. Humphrey and T. Sturgeon (2005) 'The governance of global value chains', Review of International Political Economy, 12 (1), 78-104, doi: 10.1080/096922905000 49805.

Graham, M. (2014) 'A critical perspective on the potential of the internet at the margins of the global economy', in M. Graham and W. Dutton (eds) Society and the internet: how networks of information and communication are changing our lives, Oxford: Oxford University Press, 301-18.

Granovetter, M. (1985) 'Economic action and social structure: the problem of embeddedness', Readings in Economic Sociology, 91 (3), 63-8, available at: https://sociology.stanford.edu/ sites/default/files/publications/economic_action_and_social_structure.pdf.

Gwynne, R. N. (2006) 'Export-orientation and enterprise development: a comparison of New Zealand and Chilean wine production', Tijdschrift voor Economische en Sociale Geografie, 97 (2), 138-56, doi: 10.1111/j.1467-9663.2006.00508.x.

Henderson, J., P. Dicken, M. Hess, N. Coe and H. W. Yeung (2002) 'Global production networks and the analysis of economic development', Review of International Political Economy, 9 (3), 436-64, doi: 10.1080/09692290210150842. 


\section{Christopher Foster and Mark Graham}

Hess, M. (2004) “'Spatial” relationships? Towards a reconceptualization of embeddedness', Progress in Human Geography, 28 (2), 165-86, doi: 10.1191/0309132504ph479oa.

Kaplinsky, R. and M. Morris (2001) A handbook for value chain research, Ottawa: IDRC.

Latour, B. (1999) Pandora's hope: essays on the reality of science studies, Boston, MA: Harvard University Press.

Latour, B. (2005) Reassembling the social: an introduction to actor-network-theory, Oxford: OUP.

Law, J. (1999) 'After ANT: complexity, naming and topology', The Sociological Review, 47 (S1), 1-14, doi: 10.1111/j.1467-954X.1999.tb03479.x.

Lehdonvirta, V., I. Hjorth, M. Graham and H. Barnard (2015) 'Online labour markets and the persistence of personal networks: evidence from workers in Southeast Asia', paper presented at ASA Annual Meeting, Chicago, IL, 22 August, available at: http://vili.lehdonvirta.com/ files/Online labour markets and personal networks ASA 2015.pdf.

Löfgren, O. (2003) 'The new economy: a cultural history', Global Networks, 3 (3), 239-54, doi: $10.1111 / 1471-0374.00060$.

Lüthje, B. (2002) 'Electronics contract manufacturing: global production and the international division of labor in the age of the internet', Industry and Innovation, 9 (3), 227-47, doi: $10.1080 / 1366271022000034471$.

Mahutga, M. C. (2012) 'When do value chains go global? A theory of the spatialization of global value chains', Global Networks, 12 (1), 1-21, doi: 10.1111/j.1471-0374.2011.00322.x.

Malecki, E. J. and B. Moriset (2007) The digital economy: business organization, production processes and regional developments, London: Routledge.

Murdoch, J. (1998) 'The spaces of actor-network theory', Geoforum, 29 (4), 357-74, doi: 10.1016/S0016-7185(98)00011-6.

Murphy, J. T. and P. R. Carmody (2015) Africa's information revolution: technical regimes and production networks in South Africa and Tanzania, Chichester: Wiley.

Orlikowski, W. J. (2010) 'The sociomateriality of organisational life: considering technology in management research', Cambridge Journal of Economics, 34 (1), 125-41, doi: 10.1093/cje/ bep058.

Ouma, S. (2010) 'Global standards, local realities: private agrifood governance and the restructuring of the Kenyan horticulture industry', Economic Geography, 86 (2), 197-222, doi: 10.1111/j.1944-8287.2009.01065.x.

Ponte, S. and P. Gibbon (2005) 'Quality standards, conventions and the governance of global value chains', Economy and Society, 34 (1), 1-31, doi: 10.1080/0308514042000329315.

Spinuzzi, C. (2008) Network: theorizing knowledge work in telecommunications, Cambridge: Cambridge University Press.

Stalder, F. (2006) Manuel Castells and the theory of the network society, Cambridge: Polity Press.

Sturgeon, T. J. (2002) 'Modular production networks: a new American model of industrial organization', Industrial and Corporate Change, 11 (3), 451-96, doi: 10.1093/icc/11.3.451.

Sunley, P. (2008) 'Relational economic geography: a partial understanding or a new paradigm?', Economic Geography, 84 (1), 1-26, doi: 10.1111/j.1944-8287.2008.tb00389.x.

Terranova, T. (2000) 'Free labor: producing culture for the digital economy', Social Text, 18 (2), 33-58, doi: 10.1215/01642472-18-2_63-33.

Waema, T. and C. Katua (2014) 'The promises of fibre-optic broadband in tourism and tea sectors: a pipeline for economic development in East Africa', project report, University of Nairobi, Kenya, available at: www.oii.ox.ac.uk/publications/kenya_tourism_tea.pdf.

Wrigley, N. and A. Currah (2006) 'Globalizing retail and the "new e-conomy": the organizational challenge of e-commerce for the retail TNCs', Geoforum, 37 (3), 340-51, doi: 10.1016/ j.geoforum.2005.06.003.

Yeung, H. W. (2003) 'Practicing new economic geographies: a methodological examination', Annals of the Association of American Geographers, 93 (2), 442-62, doi: 10.1111/14678306.9302011. 